\title{
Prevalência de Streptococcus suis tipo 2 por meio da técnica de reação em cadeia da polimerase em suínos abatidos no Estado do Mato Grosso
}

\author{
Prevalence of Streptococcus suis type 2 using the polimerase chain reaction in slaughtered pigs in \\ the State of Mato Grosso, Brazil
}

\author{
Ana Carolina Silva de Faria ${ }^{\mathrm{I}}$ Maria Cristina da Silva ${ }^{\mathrm{III}}$ João Xavier Oliveira Filho ${ }^{\mathrm{II}}$ \\ Juçara Tinasi de OliveiraII Daphine Ariadne Jesus de Paula ${ }^{\text {II }}$ Cristiane Silva Chitarra ${ }^{\text {III }}$ \\ Luciano Nakazato ${ }^{\mathrm{II}}$ Valéria Dutra ${ }^{\mathrm{III}} *$
}

\section{RESUMO}

Streptococcus suis é um patógeno que a afeta a produção industrial de suínos em todo o mundo. É de extrema importância, pois está associado a doenças em suínos e humanos. $O$ objetivo deste estudo foi determinar a prevalência do Streptococcus suis tipo 2 em 201 amostras de tonsilas de animais clinicamente sadios a partir da técnica de PCR. As amostras positivas foram submetidas à pesquisa do gene codificador do fator extracelular (ef). Os resultados demonstraram que a prevalência $(23,38 \%)$ foi maior que em outro estudo recentemente realizado no mesmo Estado, indicando que a PCR é um método mais sensível em relação ao isolamento bacteriano. Houve baixa ocorrência do gene ef* $(1,49 \%)$, o que mostra uma grande importância para população analisada, pois cepas negativas são potencialmente menos virulentas que cepas positivas.

Palavras-chave: Streptococcus suis tipo 2, PCR, ef, suínos.

\section{ABSTRACT}

Streptococcus suis is a pathogen that affects the industrial production of swine worldwide. It is extremely important, because it is associated with pigs and humans diseases. The aim of this study was to determine the prevalence of Streptococcus suis type 2 in 201 samples of tonsils from clinically healthy animals by the PCR technique. The samples positive for $\boldsymbol{S}$. suis type 2 were tested for the gene encoding extracellular factors (ef). The results showed that the prevalence (23.38\%) was higher than other recent survey in the State, demonstrating that the PCR is a more sensitive method in relation to the bacterial isolation. There was a low occurrence of ef* gene in samples $(1.49 \%)$ showing great importance to local swine population, because negative strains are potentially less virulent that positive strains.

Key words: Streptococcus suis type 2, PCR, ef, pigs.

\section{INTRODUÇÃO}

O Streptococcus suis é conhecido como um patógeno suíno de significância clínica na maioria dos países com indústria suína intensiva (MAROIS et al., 2007). Esse patógeno está associado a doenças em suínos, tais como meningites, artrites, pericardites, septicemia, pneumonia, morte súbita (MAROIS et al., 2007) e infecções em seres humanos (GOTTSCHALK et al., 2007).

Com base no polissacarídeo capsular, 35 sorotipos foram identificados ( 1 ao 34 e $1 / 2$ ) (CALDERARO et al., 2004; MAROIS et al., 2004; BERTHELOT-HÉRAULT et al., 2005; COSTA et al., 2005; LARA et al., 2007). Porém, estudos realizados por HILL et al. (2005) demonstraram que os sorotipos 32 e 34 podem ser classificados como Streptococcus orisratti. O sorotipo 2 é o de maior prevalência em muitos países (BOSCO etal., 2000; COSTA et al., 2005; GOTTSCHALK et al., 2007), inclusive no Brasil, principalmente nas regiões Sul e Sudeste (BARCELLOS et al., 1995; CALDERARO et al., 2004; COSTA et al., 2005; LARA et al., 2007).

O habitat natural do S. suis é o trato respiratório superior, particularmente tonsilas e cavidade nasal, bem como o trato genital e alimentar de suínos (ROBERTSON \& BLACKMORE , 1989; GOTTSCHALHK \& SEGURA, 2000; LUN et al., 2007). S. suis tipo 2 coloniza tonsilas palatinas de suínos clinicamente doentes e sadios e é transmitido por via nasal e oral (ARENDS et al., 1984).

IPrograma de Pós-graduação em Ciência Animal, Universidade Federal de Mato Grosso (UFMT), Cuiabá, MT, Brasil.

IPrograma de Pós-graduação em Ciências Veterinárias, UFMT, Cuiabá, MT, Brasil.

IIILaboratório de Microbiologia Veterinária, Hospital Veterinário, UFMT. Av. Fernando Correa da Costa s/n, Bairro Coxipó, 78060900, Cuiabá, MT, Brasil. E-mail: valdutra@ufmt.br. *Autor para correspondência. 
O isolamento de $\boldsymbol{S}$. suis para a identificação de animais portadores, a partir de tonsilas, é difícil em razão da alta contaminação desse tecido (MAROIS et al., 2007). Recentemente, tem-se utilizado o teste de Reação em Cadeia da Polimerase (PCR) para melhorar o diagnóstico de animais portadores dessa bactéria com maior sensibilidade e especificidade (WISSELINK et al., 1999).

Vários fatores de virulência têm sido descritos, tais como a cápsula (SMITH et al., 1999, 2000), "muraminidase-released-protein" (mrp), fator proteico extracelular (ef) (SMITH et al., 1992, 1997), suilisina (NORTON et al., 1999; JACOBS et al., 1996) e adesinas (DE GREEFF et al., 2002), sendo as proteínas destes genes utilizados como potenciais candidatos a vacina pela metodologia da vacina reversa (LIU et al., 2008). Amostras de sorotipo 2, positivo para os genes mrp e ef, são associadas à maior virulência (BAUMS et al., 2007), e outras variantes do gene (ef*) são consideradas menos virulentas ou associadas a infecções em seres humanos (SMITH, et al., 1993).

Tendo em vista esses fatores de virulência, o presente estudo objetivou determinar a prevalência do $S$. suis tipo 2 com a presença do gene fator proteico extracelular (ef) em tonsilas de suínos abatidos no Estado do Mato Grosso, por meio da Reação em Cadeia da Polimerase (PCR).

\section{MATERIAL E MÉTODOS}

Foram coletadas 201 amostras de tonsilas de suínos abatidos em três frigoríficos com Serviço de Inspeção Federal, durante o período de junho de 2005 a abril de 2008, oriundos de nove municípios de diferentes regiões do Estado de Mato Grosso. Essa amostragem foi baseada no programa EPI-Info 3.3.2 (DEAN, 2007), considerando os seguintes parâmetros: número de animais abatidos no Estado durante o ano de 2006 (800.000) (ABIPECS, 2006); prevalência estimada de 10,27\% (BOSCO et al., 2000); precisão absoluta de $9 \%$ e intervalo de confiança de $95 \%$. As tonsilas, uma vez coletadas, foram armazenadas individualmente em sacos plásticos, identificadas e encaminhadas em caixa isotérmica com gelo reciclável ao Laboratório de Microbiologia Veterinária para os devidos processamentos. Para extração de DNA, foi utilizado o protocolo descrito por SAMBROOK \& RUSSEL.(2004).

Para a técnica de PCR, foram utilizados os seguintes pares de oligonucleotídeos iniciadores: 16S195(s) (CAGTATTTACCGCATGGTAGATAT) e 16S489(as2) (GTAAGATACCGTCAAGTGAGAA), definido pela sequência 16S rRNA(CHATELLIER et al., 1998) e originando produtos de 294pb; cps2J-s (GTTGAGTCCTTATACACCTGTT) e cps2J-as (CAGAAAATTCATATTGTCCACC), que corresponde ao sorotipo 2, originando produtos de 459pb (MAROIS et al., 2004); (GCTACGACGGCCTCAGAAATC) e (TGGATCAACCACTGGTGTTAC) para o ef (WISSELINK et al., 1999). Esse último origina 626pb, porém pode também amplificar produtos com 1278, 1505, 2313, 2537 e 2993pb, que determinam cinco variantes do gene que codifica o ef*. Como controle negativo, foram utilizados água ultrapura e DNA de $\boldsymbol{S}$. suis tipo II gentilmente cedido pela $\mathrm{Pro}^{\mathrm{a}} \mathrm{Dr}^{\mathrm{a}}$ Agueda P.C. de Vargas (LABAC-UFSM).

A PCR foi conduzida em um volume final de $25 \mu 1$. Cada reação conteve 20 ng de DNA, solução tampão para PCR 10X (Tris-HCl 10mM pH 8,3, KCl $50 \mathrm{mM}, \mathrm{MgCl} 22,5 \mathrm{mM}), 200 \mu \mathrm{M}$ de cada dNTP, $3 \mathrm{mM}$ de cloreto de magnésio, $1 \mathrm{U}$ de Taq DNA polimerase e $25 \mathrm{pmol}$ de cada oligonucleotídeo iniciador. Os testes de PCR para 16S rRNA e cps $2 \mathrm{~J}$-s foram realizadas em 40 ciclos de desnaturação a $94^{\circ} \mathrm{C}$, por $30 \mathrm{~s}$, anelamento de primer a $60^{\circ} \mathrm{C}$, por $30 \mathrm{~s}$ e extensão a $72^{\circ} \mathrm{C}$, por $60 \mathrm{~s}$. Para o gene ef, foi realizada a PCR em 40 ciclos de desnaturação a $94,8^{\circ} \mathrm{C}$, por $1 \mathrm{~min}$, anelamento de primer a $57^{\circ} \mathrm{C}$, por $55 \mathrm{~s}$, e extensão a $72^{\circ} \mathrm{C}$, por $2 \mathrm{~min}$, e $72^{\circ} \mathrm{C}$, por $10 \mathrm{~min}$. Os produtos amplificados foram fracionados em gel de agarose $2 \%$ e corados com brometo de etídeo por $1 \mathrm{~h}$, a $125 \mathrm{~V}$, e observados em transiluminador UV. Como marcador, foi utilizado marcador de massa molecular padrão de 100 pares de base (Eurogentec, Angers, France).

\section{RESULTADOS E DISCUSSÃO}

Das 201 amostras testadas, $118(58,70 \%)$ amplificaram o gene $16 \mathrm{~S}$ rRNA. Dentre o total das amostras, 47 (23,38\%) amplificaram o gene capsular (cps2j), que corresponde ao sorotipo 2, e $3(1,49 \%)$ amplificaram o gene que corresponde ao ef. Não foram encontradas amostras positivas para o ef*.

Nos municípios analisados, as porcentagens de amostras positivas para o gene $16 \mathrm{~S}$ rRNA variam de $36,36 \%$ a $85,71 \%$. Observou-se que o S. suis tipo 2 está presente em todos os municípios estudados em uma taxa percentual que varia de $16,67 \%$ a $60 \%$.

O presente trabalho obteve uma prevalência superior à encontrada por OLIVEIRA (2008) em estudo realizado nesse mesmo Estado, utilizando-se a técnica de isolamento bacteriano. Essa maior prevalência pode ser explicada devido à dificuldade no isolamento da bactéria estudada, pois o local de colonização do $\boldsymbol{S}$. suis é coinfectado com diversos microrganismos (MAROIS et al., 2007). Outros fatores seriam a alta 
Prevalência de Streptococcus suis tipo 2 por meio da técnica de reação em cadeia da polimerase...

sensibilidade e a especificidade da técnica de PCR realizada em tonsilas de suínos (WISSELINK, et al., 2002), em comparação com o isolamento bacteriano na mesma amostra, além do fato de ser muito mais rápida de executar (WISSELINK, et al., 1999).

SWILDENS et al. (2005), no estudo de suínos abatidos na Holanda, detectaram 18\% de amostras positivas para $S$. suis tipo 2 por meio da PCR. Na França, MAROIS, et al. (2007), utilizando a PCR, encontram S. suis tipo 2 em $71 \%$ das tonsilas e $81 \%$ de swabs tonsilares de animais clinicamente doentes. Dessas mesmas amostras, foram realizadas culturas, obtendo-se resultados positivos em 57 e $72 \%$, respectivamente.

LARA et al. (2007) descreveram, em Santa Catarina (SC), uma prevalência de 55,88\% em lotes portadores. O resultado é superior ao encontrado no presente estudo. Isso pode ser explicado pelo fato de que SC apresenta uma suinocultura principalmente baseada no sistema de produção integrada diferente do sistema de criação (ciclo completo) predominante em Mato Grosso e, segundo OLIVEIRA (2008), isso influenciaria o nível sanitário do rebanho.

MARTINEZ et al. (2003) analisaram amostras de swabs de animais doentes de três diferentes Estados brasileiros. Das amostras isoladas, foram detectadas, pela técnica de PCR multiplex, amostras positivas para o gene ef*. CALDERARO et al. (2004) encontraram $72,2 \%$ de amostras positivas para ef e $20,3 \%$ para ef* de amostras brasileiras de $\boldsymbol{S}$. suis isoladas de sete diferentes Estados também de animais doentes. Esse resultado é bem superior ao encontrado neste estudo, o que pode ser considerado como um fator importante, pois as cepas ef positivas são potencialmente mais virulentas que cepas negativas (GOTTSCHALK \& SEGURA, 2000). Outro fator a ser considerado é a diferença de animais estudados, já que neste estudo foram utilizados animais sadios.

\section{CONCLUSÃO}

A prevalência de $\boldsymbol{S}$. suis tipo 2 em suínos sadios, no Estado de Mato Grosso, foi superior a outros estudos realizados. No entanto, destaca-se que, no presente estudo, foi utilizada a técnica de isolamento bacteriano, com a presença de amostras positivas para o fator ef em suínos sadios no Estado de Mato Grosso. Isso justifica a realização de outros estudos para detecção de mais fatores de virulência que podem acarretar prejuízos na atividade suinícola.

\section{AGRADECIMENTOS}

MCS foi bolsista Apoio Técnico da Fundação de Amparo à Pesquisa do Estado do Mato Grosso (FAPEMAT), e CSC foi bolsista de iniciação científica da FAPEMAT.

\section{REFERÊNCIAS}

ABIPECS. Associação Brasileira da Indústria Produtora e Exportadora da Carne suína. 2006. Capturado em 15 mar. 2008. Online. Disponível na internet: <http:// www.abipecs.org.br>.

ARENDS, J.P. et al. Carrier rate of Streptococcus suis capsular type 2 in palatine tonsils of slaughtered pigs. Journal of Clinical Microbiology, v.20, p.945-47, 1984. Disponível em: <http://jcm.asm.org/cgi/reprint/20/5/945>. Acesso em: 30 set. 2009.

BAUMS, C.G. et al. Prevalence of Streptococcus suis genotypes in wild boards of Northwestern Germany. Applied and Environmental Microbiology, v.73, n.3, p. 711-717, 2007. Disponível em: <http://aem.asm.org/cgi/reprint/73/3/711>. Acesso em: 30 set. 2009. doi: 10.1128/AEM.01800-06.

BERTHELOT-HÉRAULT, F. et al. Dilemma of virulence of Streptococcus suis: Canadian isolate 89-1591 characterized as virulent strain using a standardized experimental model in pigs. Canadian Journal of Veterinary Research, v.69, p.236240, 2005. Disponível em: <http://www.pubmedcentral.nih.gov/ picrender.fcgi? artid $=1176304 \&$ blobtype $=p d f>$. Acesso em: 30 set. 2009.

BOSCO, S.M.G. et al. Streptococcus suis tipo II em suínos e perfil de susceptibilidade a antimicrobianos. Arquivos do Instituto Biológico, v.67, p.157-160, 2000. Disponível em: $<$ http://www.biologico.sp.gov.br/docs/arq/V67_2/2.pdf $>$. Acesso em: 30 set. 2009.

CALDERARO, F.F. et al. Detecção dos genes codificadores das proteínas EF, MRP e suilisina em amostras de Streptococcus suis sorotipo 2 isoladas em suínos no Brasil. Arquivos do Instituto Biológico, v.71, p.15-19, 2004. Disponível em: $<\mathrm{http}$ ://www.biologico.sp.gov.br/docs/arq/V71_1/calderaro.pdf $>$. Acesso em: 30 set. 2009.

COSTA, A.T.R. et al. Serotyping and evaluation of the virulence in mice of Streptococcus suis strain isolated from diseased pigs. Revista do Instituto de Medicina Tropical, v.47, p.113115,2005 .

CHATELLIER, S. et al. Phylogenetic diversity of Streptococcus suis strains of various serotypes as revealed by $16 \mathrm{~S}$ rRNA gene sequence comparison. International Journal of Systematic Bacteriology, v.48, p.581-589, 1998. Disponível em: <http:/ /ijs.sgmjournals.org/cgi/content/abstract/48/2/581>. Acesso em: 30 set. 2009 . doi: $10.1099 / 00207713-48-2-581$

DEAN, A.G. et al. Epi Info ${ }^{\mathrm{TM}}$, a database and statistics program for public health professionals. Atlanta, Georgia, USA: Centers for Disease Control and Prevention, 2007. Acesso em: dez. 2008. Online. Disponível em: <http://www.cdc.gov/ epiinfo/>. 
DE GREEFF, A. et al. Contribution of fibronectin-binding protein of pathogenesis of Streptococcus suis serotype 2. Infection and Immunity, v.70, p.1319-1325, 2002. Disponível em: <http://iai.asm.org/cgi/content/full/70/3/ 1319 ? $\mathrm{maxtoshow}=\&$ H I T S $=10 \&$ hits $=10 \&$ RES U L T F O R M A T $=\&$ fu $11 \mathrm{te}$ e t $=\%$ B 5 g \& s e a r c hid $=$ $1 \&$ FIRSTINDEX $=3790 \&$ resourcetype $=$ HWFIG $>$. Acesso em: 30 set. 2009. doi: 10.1128/IAI.70.3.1319-1325.2002.

GOTTSCHALK, M.; SEGURA, M. The pathogenesis of the meningitis caused by Streptococcus suis: the unresolved questions. Veterinary Microbiology, v.76, p.259-272, 2000. Disponível em: <http://dx.doi.org/10.1016/S0378-1135(00)00250-9>. Acesso em: 30 set. 2009. doi:10.1016/S0378-1135(00)00250-9.

GOTTSCHALK, M. et al. Streptococcus suis infection in humans: the Chinese experience and the situation in North America. Animal Health Research Reviews, v.8, p.29-45, 2007. Disponível em: <http://journals.cambridge.org/action/ displayAbstract? fromPage $=$ online $\&$ aid $=1298832>$. Acesso em: 30 set. 2009 . doi: 10.1017/S1466252307001247.

HILL, J.E. et al. Biochemical analysis, cpn60 and 16S rDNA sequence data indicate that Streptococcus suis serotypes 32 and 34, isolated from pigs, are Streptococcus orisratti. Veterinary Microbiology, v.107, p.63-69, 2005. Disponível em: $<$ http:// dx.doi.org/10.1016/j.vetmic.2005.01.003>. Acesso em: 30 set. 2009. doi:10.1016/j.vetmic.2005.01.003.

JACOBS, A.A. et al. Protection of experimentally infected pigs by suilysin, the thiol-activated haemolysin of Streptococcus suis. Veterinary Record, v.139, p.225-228, 1996. Disponível em: <http://veterinaryrecord.bvapublications.com/cgi/content/ abstract/139/10/225>. Acesso em: 30 set. 2009.

LARA, A.C. et al. Prevalência de Streptococcus suis sorotipo 2 em tonsilas de suínos sadios em idade de abate no estado de Santa Catarina. Archives of Veterinary Science, v. 12, p.3134, 2007. Disponível em: <http://ojs.c3sl.ufpr.br/ojs2/ index.php/veterinary/article/viewFile/9906/6816>. Acesso em: 30 set. 2009.

LIU, L. et al. Indetification and experimental verification of protective antigens against Streptococcus suis serotype 2 based on genome sequence analysis. Current microbiology, v.58, p.11-17, 2008. Disponível em: <http://www.springerlink.com/ content/28jgk124q8t32h53/fulltext.html $>$. Acesso em: 30 set. 2009. doi: 10.1007/s00284-008-9258-x.

LUN, Z.R. et al. Streptococcus suis: an emerging zoonotic pathogen. Lancet infectious diseases, v.7, p.201-209, 2007. Disponível em: $<$ http://dx.doi.org/10.1016/S1473-3099(07)70001-4>. Acesso em:30 set 2009. doi:10.1016/S1473-3099(07)70001-4.

MAROIS, C. et al. Multiplex PCR assay for detection of Streptococcus suis species and serotypes 2 e $1 / 2$ in tonsils of live and dead pigs. Journal of Clinical Microbiology, v.42, p. 3169-3175, 2004. Disponível em: <http://jcm.asm.org/cgi/ content $/$ full $/ 42 / 7 / 3169$ ? view $=$ long\&pmid $=15243078>$. Acesso em: 30 set. 2009. doi: 10.1128/JCM.42.7.3169-3175.2004.

MAROIS, C. LE et al. Detection and molecular typing of Streptococcus suis in tonsils from live pigs in France. Canadian
Journal of Veterinary Research, v.71, p.14-22, 2007. Disponível em: <http://www.pubmedcentral.nih.gov/ articlerender.fcgi? artid $=1635993>$. Acesso em: 30 set. 2009.

MARTINEZ, G. et al. Clonal distribution of an atypical MRP+, $\mathrm{EF}^{*}$, and suilysin+ phenotype of virulent Streptococcus suis serotype 2 strains in Brazil. Canadian Journal of Veterinary Research, v.67, p.52-55, 2003. Disponível em: <http:// w w w. p u b m e d c e n t a l. n i h.g o v / picrender.fcgi $?$ artid $=227027 \&$ blobtype $=p d f>$. Acesso em: 30 set. 2009.

NORTONA, P.M. et al. Epithelial invasion and cell lysis by virulent strains of Streptococcus suis is enhanced by the presence of suilysin. FEMS immunology and medical microbiology, v.26, p.2535, 1999. Disponível em: <http://www3.interscience.wiley.com/ cgi-bin/fulltext/119081646/HTMLSTART>. Acesso em: 30 set. 2009. doi 10.1111/j.1574-695X.1999.tb01369.x

OLIVEIRA, J.T. Prevalência e perfil de sensibilidade antimicrobiana de Streptococcus suis sorotipo 2 em suínos abatidos em Mato Grosso. 2008. 52f. Dissertação (Mestrado em Ciências Veterinárias) - Curso de Pós-graduação em Ciências Veterinárias, Universidade Federal de Mato Grosso, MT.

ROBERTSON, I.D.; BLACKMORE, D.K. Occupational exposure to Streptococcus suis type 2. Epidemiology and infection, v.103, p.157-164, 1989.

SAMBROOK, J., RUSSEL, D.W. Isolation of high-molecularweight DNA from mammalian cells using proteinase $\mathrm{K}$ an phenol. In: Molecular coloning: a laboratory manual. 3.ed. New York: Cold spring Habor Laboratory, 2001. V.1, cap.6, p.6.4-6.12.

SMITH, H.E. et al. Cloning and nucleotide sequence of the gene encoding the 136-kilodalton surface protein (muramidasereleased protein) of Streptococcus suis type 2. Infection and immunity, v.60, p.2361-2367, 1992. Disponível: <http:// w w w. p u b m e d c e $\mathrm{t}$ r a 1. n i h.g o v/ picrender. fcgi artid $=257166 \&$ blobtype $=p d f>$. Acesso em: 30 set. 2009.

SMITH, H.E. et al. Repeats in an extracellular protein of weakly pathogenic strains of Streptococcus suis type 2 are absent in pathogenic strains. Infection and immunity, v.61, p.3318-3326, 1993. Disponível em: <http://iai.asm.org/cgi/ reprint/61/8/3318.pdf>. Acesso em: 30 set. 2009.

SMITH, H.E. et al. Virulence markers of Streptococcus suis type 1 and 2. Advances in experimental medicine and biology, v.418, p.651-655, 1997.

SMITH, H.E. et al. Identification and characterization of the cps locus of Streptococcus suis serotype 2: the capsule protects against phagocytosis and is an important virulence factor. Infection and immunity, v.67, p.1750-1756, 1999. Disponível em: <http://iai.asm.org/cgi/content/full/67/4/ 1750 ?ck $=$ nck $>$. Acesso em: 30 set. 2009.

SMITH, H.E. et al. The cps locus of Streptococcus suis serotype 2: genetic determinant for the synthesis of sialic acid. Microbial 
pathogenesis, v.29, p.127-134, 2000. Disponível em: <http:/ /dx.doi.org/10.1006/mpat.2000.0372>. Acesso em: 30 set. 2009. doi:10.1006/mpat.2000.0372.

SWILDENS, B. et al. Detection of extracellular factor-positive Streptococcus suis serotype 2 strains in tonsillar swabs of live sows by PCR. Veterinary Microbiology, v. 109, p.223-228, 2005. Disponível em: <http://dx.doi.org/10.1016/j.vetmic.2005.04.024>. Acesso em 30 set. 2009. doi:10.1016/j.vetmic.2005.04.024.

WISSELINK, H.J. et al. Detection of Virulence Strains of Streptococcus suis type 2 and Highly Virulent Strain of
Streptococcus suis type 1 in Tonsilar Specimes of Pigs by PCR. Veterinary Microbiology, v.67, p.143-157, 1999. Disponível em: http://dx.doi.org/10.1016/S0378-1135(99)00036-X. Acesso em 30 set. 2009. doi:10.1016/S0378-1135(99)00036-X.

WISSELINK, H.J. et al. Multiplex PCR assays for simultaneous detection of six major serotypes and two virulence-associated phenotypes of Streptococcus suis in tonsilar specimens from pigs. Journal of Clinical Microbiology, v.40, p.2922-2929, 2002. Disponível em: $<$ http://jcm.asm.org/cgi/content/full/40/ 8/2922>. Acesso em 30 set. 2009. doi: 10.1128/ JCM.40.8.2922-2929.2002 